\title{
JATROPHA OIL WITH IRON NANOPARTICLES APPLICATION IN DRILLING PROCESSES
}

\author{
Veikko Shalimba ${ }^{a, *}$, Vít Sopko ${ }^{b}$ \\ a Jan Evangelista Purkyně University in Ústí nad Labem, Faculty of Mechanical Engineering, Pasteurova 3334/7, \\ 40001 Ústí nad Labem, Czech Republic \\ ${ }^{b}$ Czech Technical University in Prague, Faculty of Nuclear Sciences and Physical Engineering, Department of \\ Physical Electronics, Břehová 7, 11519 Prague 1, Czech Republic \\ * corresponding author: veikko12@yahoo.com
}

\begin{abstract}
A performance of heat transfer fluids has a substantial influence on the size, weight and cost of heat transfer systems, therefore, a high-performance heat transfer fluid is very important in many industries. Over the last decades, nanofluids have been developed. According to many researchers and publications on nanofluids, it is evident that nanofluids have a high thermal conductivity. The aim of this experimental study was to investigate the change of the workpiece temperature during drilling using Jatropha oil with iron nanoparticles and water with iron nanoparticles as lubricating and cooling fluids. These experiments were carried out with samples of nanofluid with different nanoparticles volume ratio, such as samples $J N 1, J N 5$ and $J N 10$ of iron nanoparticles in the base Jatropha oil with a nanoparticle volume fraction of $1 \%, 5 \%$ and $10 \%$ respectively and samples $W N 1, W N 5$ and $W N 10$ of iron nanoparticles in the base water with a nanoparticle volume fraction of $1 \%, 5 \%$ and $10 \%$ respectively.
\end{abstract}

KEYWORDS: Jatropha oil, nanofluids, nanoparticles, temperature, drilling.

\section{INTRODUCTION}

Cooling is a technical challenge that is faced by many high technology industries today due to the rising demands of modern technologies. Conventional heat transfer fluids have a low thermal conductivity that limits their applications in high technology industries, therefore, there is an urgent need for more effective heat transfer fluids in terms of performance and heat storage capacity. Many ideas have been implemented and many research activities have been carried out attempting to improve the thermal properties of heat transfer fluids. The thermal conductivity of heat transfer fluids can be enhanced by the use of metallic or non-metallic nanoparticles in a base fluid 114. The resulting mixture is commonly known as a nanofluid. This concept has attracted the attention of many researches worldwide into researching the nanofluids due to their exciting thermal properties and their wide application in numerous fields, such as microelectronics, transportation, manufacturing, medicine, mining and energy.

A nanofluid is a fluid containing nanometer-sized particles. The nanoparticles used in a base fluid are normally made from metals, oxides, carbides or carbon nanotubes [5, 6]. Common conventional base fluids are water, ethylene glycol or oil. The key question still lingers, concerning the best nanoparticle and base fluid pairing. According to many publications, a nanofluid is considered to be the next-generation heat transfer fluid as it possesses good thermal properties (a high thermal conductivity, thermal diffusivity and convective heat transfer coefficients) as compared to those of a conventional fluid like water or oil [5, 7].

In this study, an application of Jatropha oil with iron nanoparticles in drilling process was investigated and compared to that of a water with iron nanoparticle nanofluids with a similar volume concentration of nanoparticles. Drilling is a cutting process that uses a drill bit to cut a hole of a circular cross-section in solid materials. Both rotating force and a downward pushing force are needed for drilling. However, drill bits generate a lot of heat energy in the process of the metal cutting. The excessive heat generation during the drilling process causes dullness and reduces the drill bit's effective life span. The cutting fluid is sometimes used to cool down the tool and the workpiece. Besides cooling, cutting fluids also aid the cutting process by minimizing the cutting forces thus saving energy and, by lubricating the interface, the contact between the tool's cutting edge and the workpiece. The lubrication also helps to improve the surface finish and prevents the chips from being welded onto the tool.

Most metalworking and machining processes can benefit from the use of a cutting fluid, depending on the workpiece material. One of the main properties that are sought after in a good cutting fluid is the ability to keep the workpiece at a stable temperature. The aim of this experimental investigation was to determine the change of the workpiece temperature during drilling using Jatropha oil with iron nanoparticles and water with iron nanoparticles as lubricating 
and cooling fluids in order to ascertain the cooling properties of both cooling fluid types.

\section{SAMPLES PREPARATION AND CHARACTERIZATIONS}

In this experimental study, nanofluids samples were prepared employing the two-step technique, where the nanoparticles used are produced as a dry powder. Afterwards, the powder at a nanoscale size was dispersed into the base fluids. According to nanofluids researchers, one of the major problems encountered in the preparation of nanofluids is the formation of clusters of particles which leads to a poor dispersion, therefore, a high shear mixer was used in order to break up agglomerates and give more uniform dispersions. However, no dispersant or surfactants were used to stabilize the nanofluid samples.

Six nanofluid samples with different volume ratio were selected as shown in Table11 Samples JN1, JN5 and $J N 10$ of iron nanoparticles in the base Jatropha oil with a different volume fraction of $1 \%, 5 \%$ and $10 \%$ respectively. Samples $W N 1, W N 5$ and $W N 10$ of iron nanoparticles in the base water with a different volume fraction of $1 \%, 5 \%$ and $10 \%$ respectively. Sample $N W 1, N W 5$ and $N W 10$ are selected mainly for a comparison purpose. Moreover, another two samples without iron nanoparticles have been selected for the comparison purpose, i.e. oil-water emulsion and undiluted Jatropha oil, E100 and JN100 respectively. Oil-water emulsion used in this work was purchased in the Czech Republic.

The blend ratios were selected according to ratios used in previous publications and iron nanoparticles were selected due to the ease of suspension and availability in the market. Jatropha oil is a new material that is being researched for new applications. Water with iron nanoparticles samples were chosen because, in general, water is the heat transfer medium for heat exchangers, because of its availability and good thermo-physical properties.

Iron nanoparticles with a diameter of $25 \mathrm{~nm}$ and spherical shape were supplied by Nano Iron, s.r.o, Czech Republic. Jatropha oil used in this work is produced by the department of Mechanical Engineering at the University of Applied Science and Technology in Namibia. Samples of nanoparticles in the base Jatropha oil as well as in the base water were prepared at the laboratory of Nano Iron s.r.o. According to the safety regulation EC.: 19017/2006, nanofluid samples used in this experiment were classified as not dangerous materials under the act on chemical substances and preparations. Nanofluid samples were stored in a cool place with a temperature between $1-5^{\circ} \mathrm{C}$, in order to avoid excess pressure built-up in the sample bottles. Nanofluid samples were kept in $500 \mathrm{ml}$ tightly sealed plastic bottles.

Jatropha oil was selected as the primary base fluid, to study potential applications of this oil, which is produced in large amount in Southern African Development Community (SADC) member states including Namibia. The water was selected as the base fluid for comparison purposes, since water is widely used in heat transfer applications. However, the water used as the base fluid in these experiments was distilled in order to avoid the presence of ions which might have an impact on the thermo-physical properties and reduce the lifespan of the samples. Iron nanoparticles were employed as dispersed phase since they are easily produced as nanoparticles and their availability in the market. In addition, the iron nanoparticles were used also due to their high thermal conductivity.

\section{EXPERIMENTAL METHOD}

The Experimental results of drilling tests for all measurement samples are depicted in Tables 2 - 9 and Figures $3-10$.

Figures $3-10$ show the change in the temperature during drilling in specimens submerged in fluid samples of E100, J100, JN1, JN5, JN10,WN1, WN5, $W N 10$. The graphs present both the increase and the decline in the temperature during the drilling and after the drilling was completed. Figure 11 compares results of samples $E 100, J 100, J N 1, J N 5$, JN10, WN1, WN5, WN10.

During the experimental tests, the temperature for all samples increased gradually, reaching a peak and decreasing slowly after the drilling depth of $10 \mathrm{~mm}$ was completed. Samples with the Jatropha oil with iron nanoparticles $J N 1, J N 5$ and $J N 10$ had a shorter drilling time and a lower peak temperature than the sample with the oil-water emulsion E100, and samples with water with nanoparticles as shown in Figure 11 . this indicates a good lubrication, anti-wear properties and cooling performance. The shortest drilling time and the lowest peak temperature was recorded during the experimental investigations of the sample $J N 10$ (with a drilling time of 29 seconds and a peak temperature of $33.3^{\circ} \mathrm{C}$, as shown in Figure 7). Samples with water with iron nanoparticles had longer drilling times and higher peak temperatures than the samples with oil-water emulsion E100. The longest drilling time and the highest peak temperature was recorded on the experimental investigations of sample $W N 10$ (with a drilling time of 95 seconds and a peak temperature of $42.4^{\circ} \mathrm{C}$, as shown in Figure 10. No wear was observed on the main cutting edges and the dead centre of HSS drill bits for all fluid samples.

\section{Conclusion}

The experimental study was conducted to investigate the application of Jatropha oil with iron nanoparticles in drilling processes. According to the presented results, the following conclusions are drawn:

- The addition of the nanoparticle concentration in Jatropha oil improves the lubrication and cooling performance. 


\begin{tabular}{lcc}
\hline Sample & Fluid volumetric fraction [\%] & Nanoparticles volumetric fraction [\%] \\
\hline E100 & 100 & - \\
$J 100$ & 100 & - \\
$J N 1$ & 99 & 1 \\
$J N 5$ & 95 & 5 \\
$J N 10$ & 90 & 10 \\
$W N 1$ & 99 & 1 \\
$W N 5$ & 95 & 5 \\
$W N 10$ & 90 & 10 \\
\hline
\end{tabular}

TABLE 1. Sample characterization.

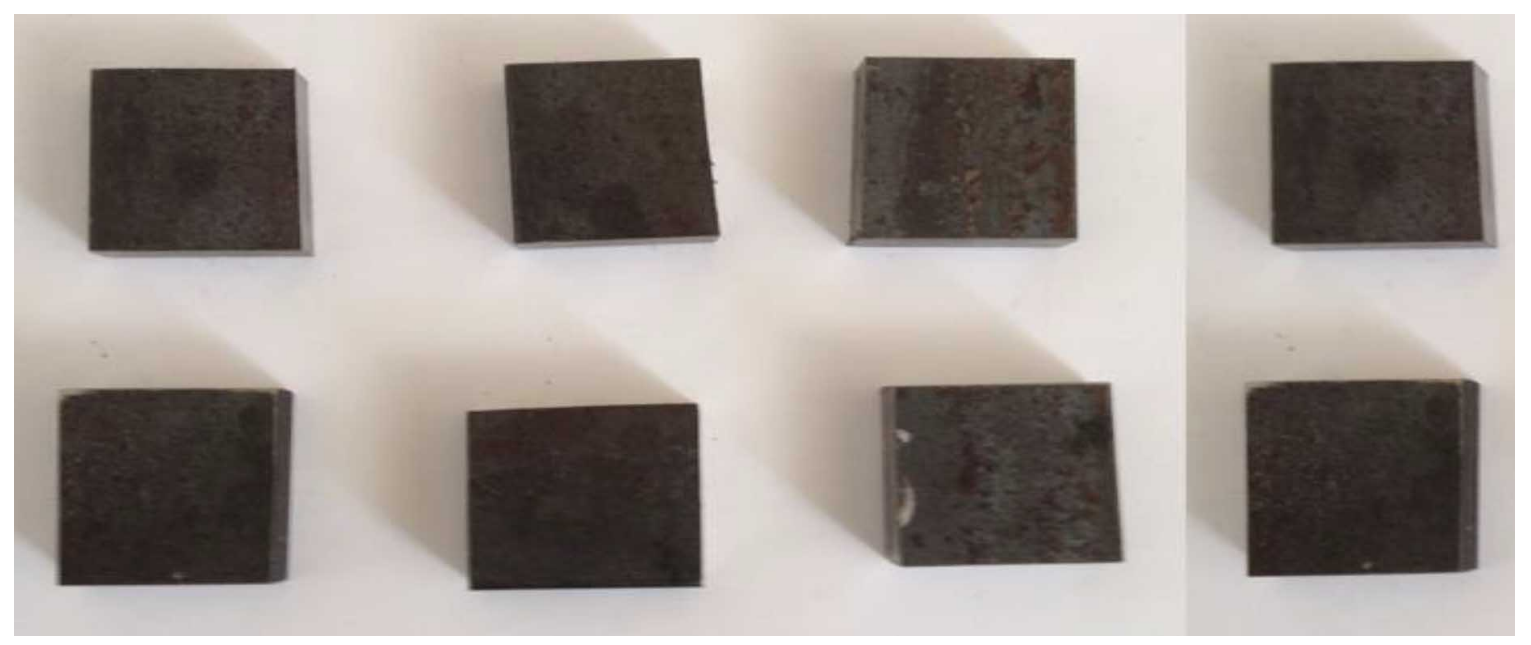

FiguRE 1. Workpieces.

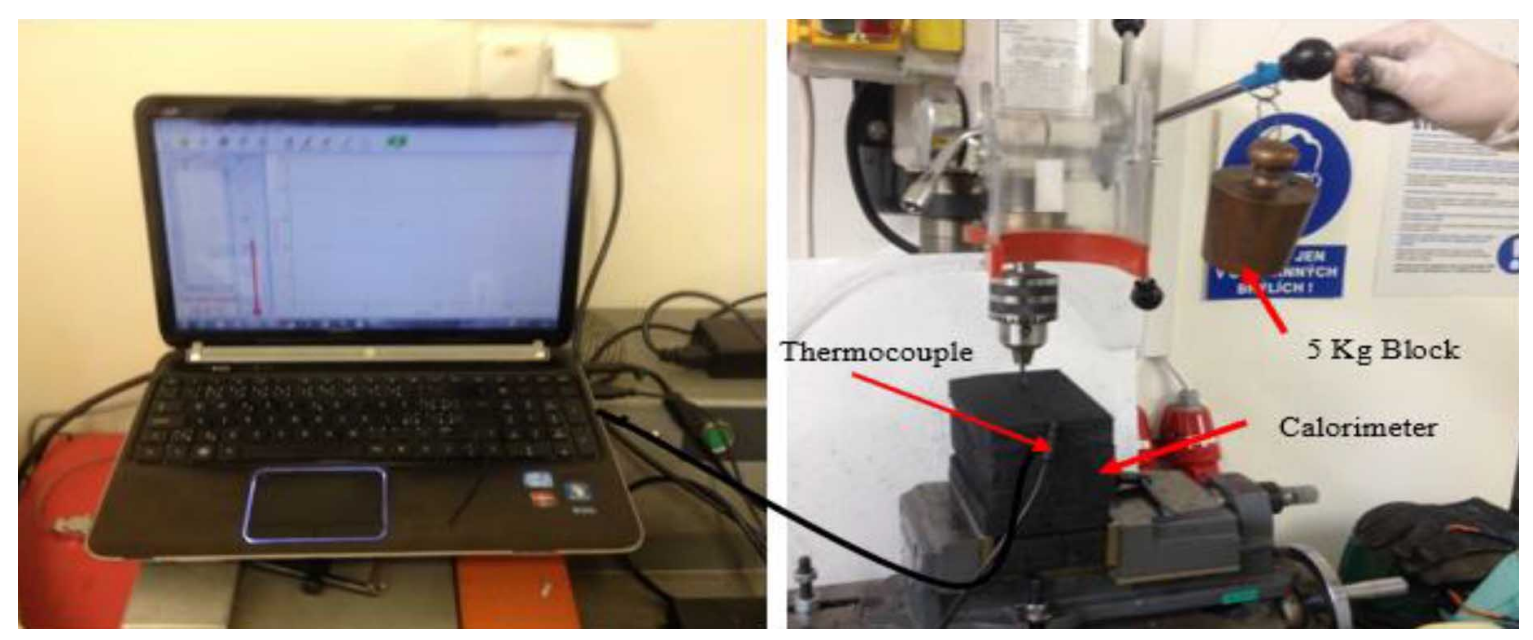

FiguRE 2. Experimental setup for measurement of temperature in drilling process.

\begin{tabular}{lccccccccc}
\hline Time $[\mathrm{s}]$ & 0 & 10 & 20 & 30 & 40 & 50 & 60 & 70 & 80 \\
Average temperature $\left[{ }^{\circ} \mathrm{C}\right]$ & 24.08 & 25.41 & 28.35 & 30.18 & 31.41 & 32.26 & 33.37 & 34.18 & 32.87 \\
Standard deviation $\left[{ }^{\circ} \mathrm{C}\right]$ & 0 & 0.070 & 0.089 & 0.074 & 0.086 & 0.087 & 0.086 & 0.046 & 0.073 \\
\hline
\end{tabular}

TABle 2. Change in temperature vs. time E100.

\begin{tabular}{lcccccccccc}
\hline Time $[\mathrm{s}]$ & 0 & 10 & 20 & 30 & 40 & 50 & 60 & 70 & 80 & 90 \\
Average temperature $\left[{ }^{\circ} \mathrm{C}\right]$ & 24.62 & 24.06 & 25.15 & 26.97 & 28.88 & 30.57 & 31.81 & 33.60 & 35.60 & 35.94 \\
Standard deviation $\left[{ }^{\circ} \mathrm{C}\right]$ & 0 & 0.038 & 0.002 & 0.007 & 0.020 & 0.031 & 0.040 & 0.007 & 0.022 & 0.065 \\
\hline
\end{tabular}

TABLE 3. Change in temperature vs. time J100. 


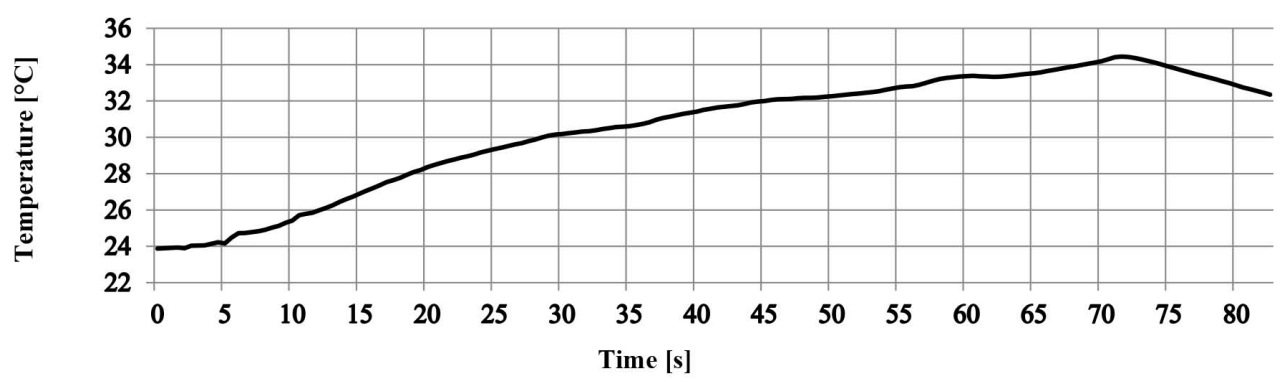

Figure 3. Change in temperature vs. time - E100.

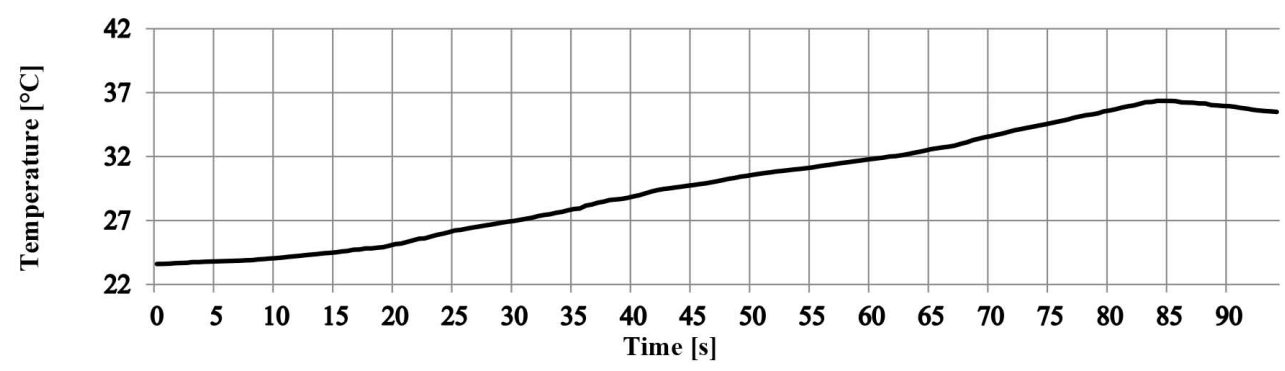

Figure 4. Change in temperature vs. time - J100.

\begin{tabular}{lccccccccc}
\hline Time $[\mathrm{s}]$ & 0 & 10 & 20 & 30 & 40 & 50 & 60 & 70 & 80 \\
Average temperature $\left[{ }^{\circ} \mathrm{C}\right]$ & 23.60 & 24.07 & 25.00 & 26.56 & 28.49 & 30.48 & 31.81 & 33.10 & 32.87 \\
Standard deviation $\left[{ }^{\circ} \mathrm{C}\right]$ & 0 & 0.037 & 0.006 & 0.059 & 0.063 & 0.041 & 0.040 & 0.048 & 0.008 \\
\hline
\end{tabular}

TABle 4. Change in temperature vs. time - JN1.

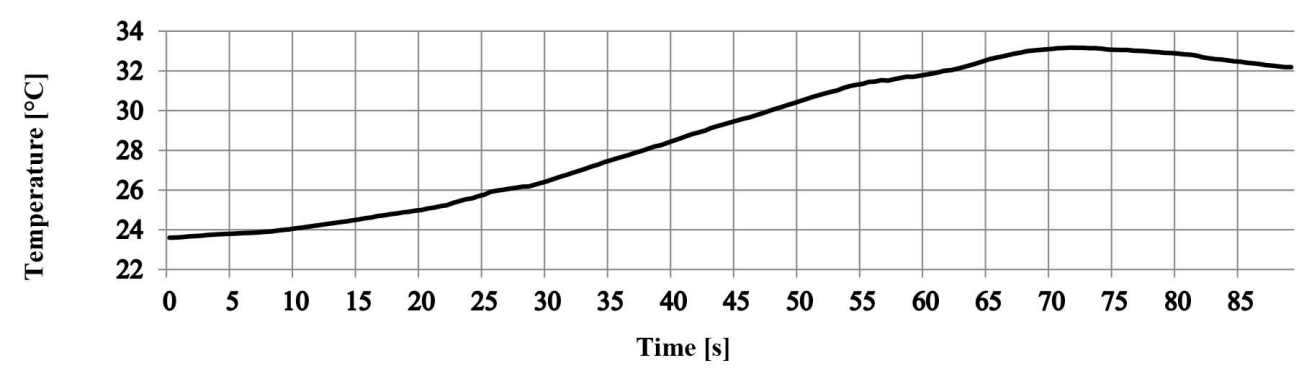

Figure 5. Change in temperature vs. time - JN1.

\begin{tabular}{lcccccc}
\hline Time $[\mathrm{s}]$ & 0 & 10 & 20 & 30 & 40 & 50 \\
Average temperature $\left[{ }^{\circ} \mathrm{C}\right]$ & 23.67 & 24.94 & 28.46 & 32.45 & 33.55 & 33.28 \\
Standard deviation $\left[{ }^{\circ} \mathrm{C}\right]$ & 0 & 0.050 & 0.069 & 0.064 & 0.078 & 0.088 \\
\hline
\end{tabular}

TABLE 5. Change in temperature vs. time - JN5.

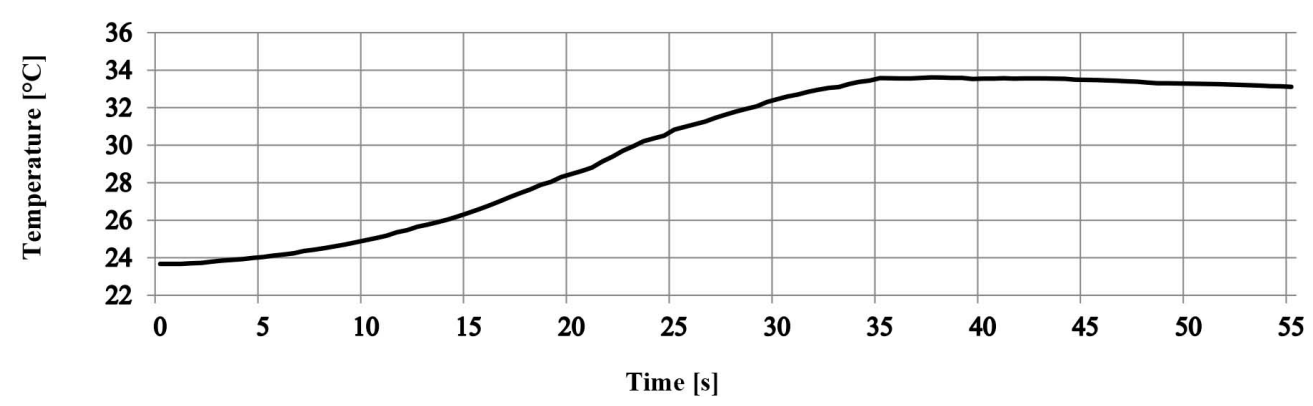

Figure 6. Change in temperature vs. time - JN5. 


\begin{tabular}{lccccc}
\hline Time $[\mathrm{s}]$ & 0 & 10 & 20 & 30 & 40 \\
Average temperature $\left[{ }^{\circ} \mathrm{C}\right]$ & 23.64 & 24.57 & 28.23 & 33.36 & 32.88 \\
Standard deviation $\left[{ }^{\circ} \mathrm{C}\right]$ & 0 & 0.023 & 0.031 & 0.042 & 0.012 \\
\hline
\end{tabular}

TABle 6. Change in temperature vs. time - JN10.

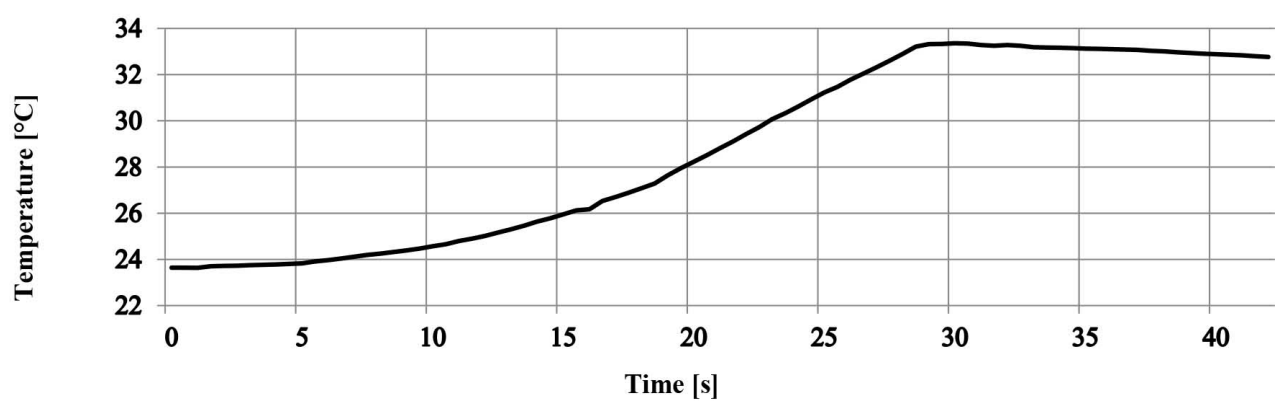

Figure 7. Change in temperature vs. time - JN10.

\begin{tabular}{lccccccccccc}
\hline Time [s] & 0 & 10 & 20 & 30 & 40 & 50 & 60 & 70 & 80 & 90 & 100 \\
Avg. temperature $\left[{ }^{\circ} \mathrm{C}\right]$ & 23.58 & 24.78 & 26.75 & 29.02 & 31.59 & 33.52 & 34.47 & 35.32 & 36.73 & 37.73 & 37.82 \\
Std. deviation $\left[{ }^{\circ} \mathrm{C}\right]$ & 0 & 0.047 & 0.410 & 0.040 & 0.500 & 0.044 & 0.049 & 0.430 & 0.049 & 0.049 & 0.053 \\
\hline
\end{tabular}

TABLE 7. Change in temperature vs. time - WN1.

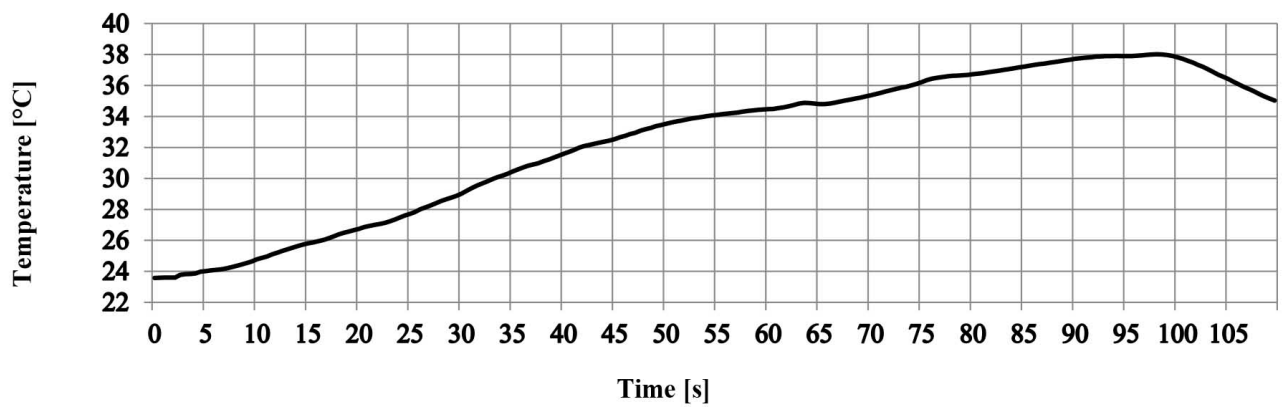

Figure 8. Change in temperature vs. time - WN1.

\begin{tabular}{lccccccccccc}
\hline Time [s] & 0 & 10 & 20 & 30 & 40 & 50 & 60 & 70 & 80 & 90 & 100 \\
Avg. temperature $\left[{ }^{\circ} \mathrm{C}\right]$ & 23.60 & 29.34 & 29.93 & 30.93 & 32.05 & 33.51 & 34.68 & 36.15 & 37.83 & 39.22 & 39.25 \\
Std. deviation $\left[{ }^{\circ} \mathrm{C}\right]$ & 0 & 0.059 & 0.059 & 0.061 & 0.068 & 0.069 & 0.068 & 0.084 & 0.074 & 0.071 & 0.057 \\
\hline
\end{tabular}

TABLE 8. Change in temperature vs. time - WN5.

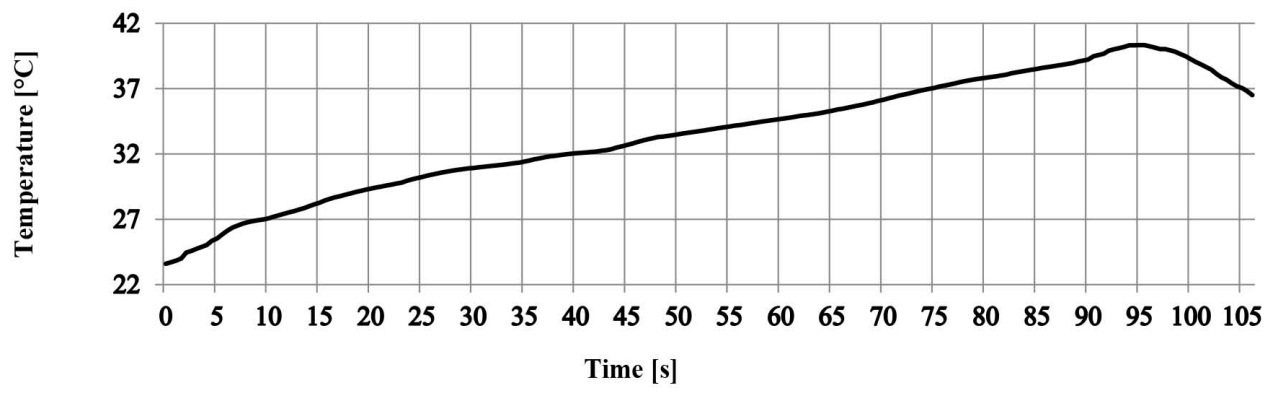

FiguRE 9. Change in temperature vs. time - WN5.

\begin{tabular}{lccccccccccc}
\hline Time $[\mathrm{s}]$ & 0 & 10 & 20 & 30 & 40 & 50 & 60 & 70 & 80 & 90 & 100 \\
Avg. temperature $\left[{ }^{\circ} \mathrm{C}\right]$ & 23.55 & 25.44 & 28.33 & 31.61 & 33.94 & 36.26 & 38.00 & 40.21 & 41.69 & 42.20 & 40.75 \\
Std. deviation $\left[{ }^{\circ} \mathrm{C}\right]$ & 0 & 0.056 & 0.053 & 0.043 & 0.046 & 0.046 & 0.058 & 0.065 & 0.065 & 0.047 & 0.055 \\
\hline
\end{tabular}

TABLE 9. Change in temperature vs. time - WN10. 


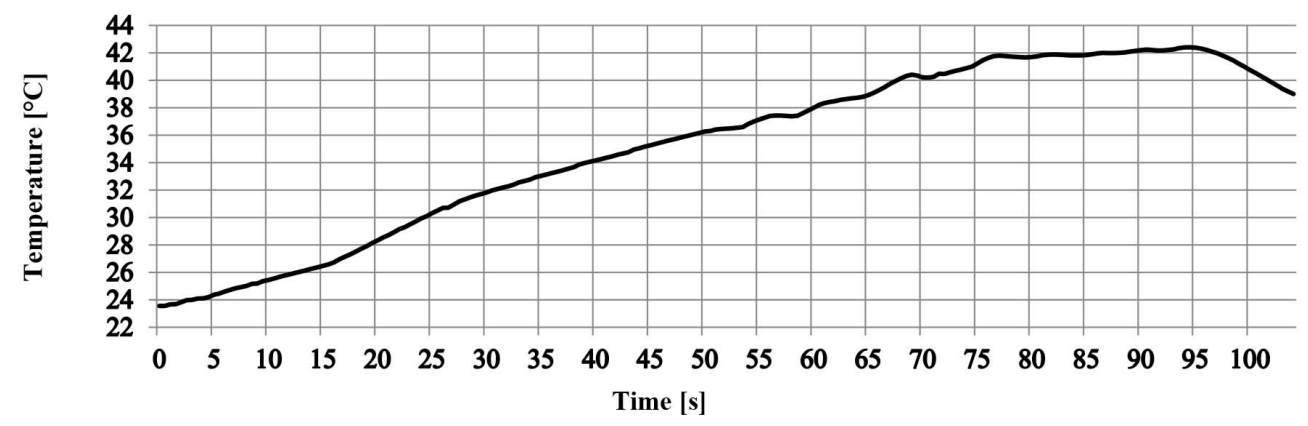

Figure 10. Change in temperature vs. time - WN10.

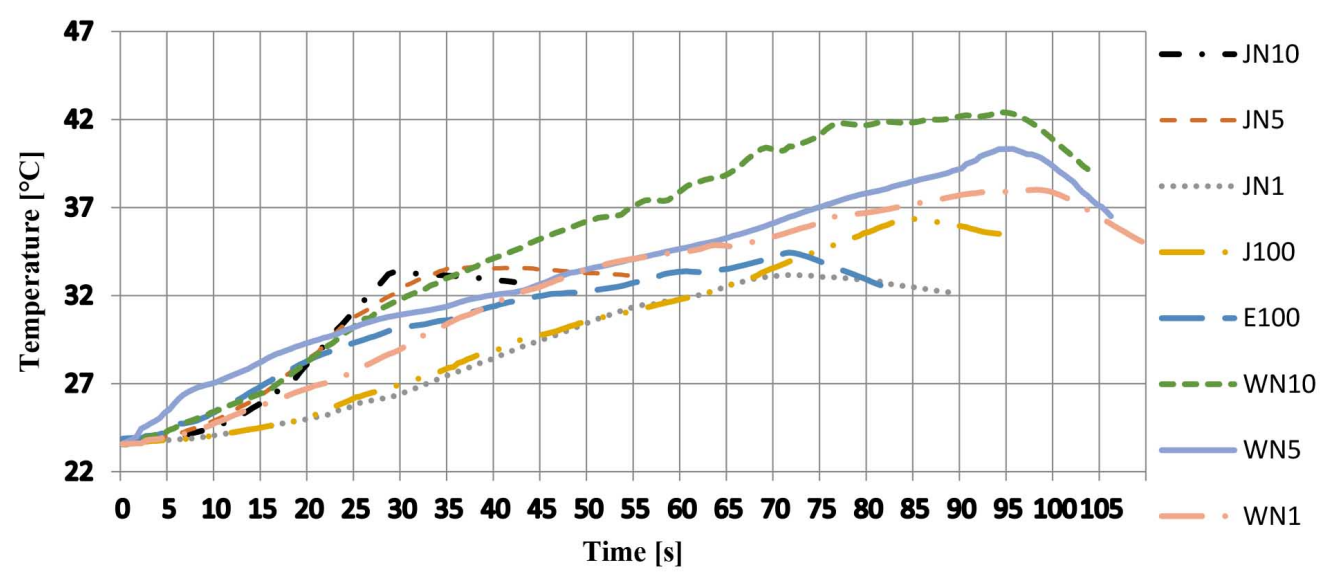

Figure 11. Change in temperature vs. time - comparison.

- During the drilling experimental tests, the temperature for all samples increased gradually, reaching a peak and then decreasing slowly after a drilling depth of $10 \mathrm{~mm}$ was reached.

- No wear was observed on the main cutting edges and the dead centre of HSS drill bits for all fluid samples.

\section{REFERENCES}

[1] S. Choi, J. Eastman. Enhancing thermal conductivity of fluids with nanoparticles. In Proceedings of the ASME Mechanical Engineering Congress and Exposition, pp. 99-104. USA, 1995.

[2] K. Das, S. Choi, T. Praddep (eds.). Nanofluids Science and Technology. John Wiley \& Son, New Jersey, 2007.

[3] E. Timofeeva. Nanofluids for heat transfer - Potential and engineering strategies. In Two Phase Flow, Phase Change and Numerical Modeling, pp. 435-450. 2011. DOI:10.5772/22158
[4] A. Wakif, Z. Boulahia, R. Sehaqui. Numerical study of the onset of convection in a newtonian nanofluid layer with spatially uniform and non uniform internal heating. Journal of Nanofluids 6:136-148, 2017. DOI:10.1166/jon.2017.1293

[5] S. OZERINC. Heat transfer enhancement with nanofluids. Master's thesis, School of Natural and Applied Science, Middle East Technical University, 2010.

[6] W. Minkowycz, E. Sparrow, J. Abraham (eds.). Nanoparticle Heat Transfer and Fluid Flow, vol. 4. Taylor \& Francis Group, New York, 2013.

[7] M. Pastoriza Gallego, L. Lugo, J. L. Legido Soto, M. Piñeiro. Thermal conductivity and viscosity measurements of ethylene glycol-based $\mathrm{al}_{2} \mathrm{O}_{3}$ nanofluids. Nanoscale Research Letters 6:221, 2011. DOI:10.1186/1556-276X-6-221 